\title{
Desenvolvimento de sistema de baixo custo para monitoramento de integridade estrutural
}

\section{Development of a low cost system for structural health monitoring}

\author{
João Batista Lamari Palma e Silva ${ }^{1}$, Ana Elisabete Paganelli Guimarães de Avila Jacintho ${ }^{1}$, \\ Nadia Cazarim da Silva Forti ${ }^{1}$, Lia Lorena Pimentel ${ }^{1}$, \\ Omar Carvalho Branquinho ${ }^{1}$
}

\footnotetext{
${ }^{1}$ CEATEC - Centro de Ciências Exatas, Ambientais e de Tecnologia, da Pontifícia Universidade Católica de Campinas, Rua Professor Doutor Euryclides de Jesus Zerbini, n.1516, Campinas, SP, Brasil. e-mail: lamaripalma@hotmail.com, anajacintho@gmail.com, nadiacazarim@yahoo.com.br, lialorenapimentel@gmail.com, omar.branquinho@gmail.com
}

\section{RESUMO}

O Monitoramento da Integridade Estrutural (MIE) pode ser utilizado para avaliar as condições de integridade de uma estrutura, ou ainda para verificar modelos de comportamento da mesma. Os atuais sistemas de monitoramento aplicados em grandes estruturas, contam com inúmeros sensores, dos mais variados tipos, que formam redes de comunicação, em alguns casos sem fio, até sistemas automatizados de aquisição de dados, do inglês data acquisition (DAQ) e processamento dos resultados, o que inclusive permite a realização de um monitoramento em tempo real e remoto. Entretanto, muitas das tecnologias empregadas nestes sistemas, são de custo relativamente alto, e carecem de conhecimento específico para operação, o que em alguns casos, torna sua utilização inviável. Neste contexto, foi desenvolvido um sistema $D A Q$ com um hardware a partir da plataforma Arduino, associada a um software mobile para smartphones, que via Bluetooth, envia e recebe informações do Arduino, para aquisição de dados de deformação, deslocamento e força, da estrutura monitorada, com transmissão de dados em tempo real via internet. Foram realizados ensaios de flexão em lâminas metálicas e vigas de concreto armado, com o uso de extensômetros, transdutores de deslocamento e célula de carga, sendo os dados aquisitados por um equipamento comercial de referência e o sistema desenvolvido nesta pesquisa, com a comparação entre os mesmos, onde se obtiveram resultados satisfatórios.

Palavras-chave: Monitoramento da Integridade Estrutural; Deformação; Deslocamento; Sistema de Baixo Custo.

\begin{abstract}
Structural Health Monitoring (SHM) can be used to evaluate the condition of the structure's integrity, or so far to verify its device's performance. The current monitoring systems applied in large structures set up with numerous sensors, and the most varied types, which form compose network communication, in some cases wireless, even in to automated systems of data acquisition (DAQ) and processing of the results, which allow real-time and remote monitoring. However, many of the technologies used in these systems are relatively expensive and require specific operating knowledge, which in some cases makes their use impracticable. In this context, a DAQ system was developed with hardware from the Arduino platform, associated to mobile software for smartphone, which via Bluetooth, send and receive information from Arduino, to acquire strain, displacement and force data from the monitored structure, with real-time data transmission via the internet. Bending tests were conducted in metallic cantilever and reinforced concrete beams using strain gages, displacement transducers and load cell, with data acquired by commercial reference equipment and the system of this research. Comparing themselves with which satisfactory results were obtained.
\end{abstract}

Keywords: Structural Health Monitoring; Strain; Displacement; Low Cost System

\section{INTRODUÇÃO}

O Monitoramento da Integridade Estrutural (MIE), tem por finalidade monitorar o comportamento da estrutu- 
ra, bem como verificar modelos analíticos e numéricos utilizados na concepção de uma estrutura solicitada sob várias condições de carregamentos, inclusive com o intuito de se verificar a ocorrência de danos ou deteriorações [1].

A exemplo do monitoramento em pontes, o mesmo tem por objetivo constatar a existência de danos, para se avaliar a necessidade de se promover intervenções nas estruturas, que podem ser de simples reparos e reformas a interdição em casos em que haja risco aos usuários, ou até mesmo a demolição das estruturas quando intervenções se mostrarem inviáveis [2].

Por meio do MIE é realizada a aquisição e compilação dos dados provenientes das estruturas, os quais são posteriormente analisados de forma sistêmica, o que permite a detecção precoce de danos estruturais, bem como a verificação de modelos teóricos referentes ao comportamento da estrutura [3].

Um mesmo sistema de MIE pode ter por objetivo emitir alertas quanto às condições da estrutura, bem como coletar dados para questões científicas, a exemplo de grandes construções urbanas, como pontes, túneis, contenções e torres de telecomunicação, onde ocorre o monitoramento da estrutura e de seus materiais [4].

Entretanto, o MIE não se limita somente a construções recentes. Sua utilização tem se despontado no ramo de avaliação de construções históricas, até mesmo para detecção de danos em estágios iniciais, o que permite efetuar intervenções antes do agravamento das condições de integridade da estrutura [5].

A utilização do monitoramento estrutural tem sido implementada de forma holística ao ser associada ao monitoramento ambiental e energético das construções, o que ainda é objeto de poucos estudos deste monitoramento integrado e em tempo real, visando melhorar o desempenho das edificações, no sentido de se promover edifícios mais seguros, saudáveis, sustentáveis e confortáveis [6].

A popularização do MIE junto a grandes construções também tem ocorrido em função da miniaturização de componentes eletrônicos, bem como em razão da evolução de algoritmos empregados nos sistemas de análise de imagens digitais [4]. Entretanto a implementação de redes de sensores para monitoramento estrutural é algo bastante caro e demanda de espaço físico para sua implantação, principalmente nos casos de redes de sensores cabeadas [7].

Equipamentos de aquisição de dados são encontrados no mercado, contudo o custo dos mesmos é relativamente alto, o que leva à utilização da plataforma Arduino como solução de baixo custo, para desenvolvimento de sistemas de aquisição de dados, empregada em conjunto com outros dispositivos eletrônicos, como amplificadores operacionais de sinais [8].

O Arduino consiste em uma plataforma de prototipagem eletrônica de códigos abertos, composta por hardware e software de fácil uso, atualmente aplicada a uma infinidade de projetos, como sendo o cérebro das mesmas. Tais como aplicações que vão desde o controle de LED's (Light Emitting Diode) e motores, até mesmo implementações em Internet of Things (IoT), ou seja, de aplicações cotidianas até instrumentos científicos complexos [9].

O objetivo principal deste estudo é desenvolver um sistema de baixo custo, para monitoramento de deformações e deslocamentos em estruturas, mediante utilização da plataforma Arduino, bem como realizar testes em estruturas de concreto armado.

\subsection{Sistemas de Aquisição de Dados}

A aquisição de dados compreende um sistema que inclui a leitura de dados dos sensores, conversão e disponibilização destes dados ao usuário. Este sistema descrito refere-se a um sistema informatizado, também conhecido como computadorizado, entretanto estes sistemas podem ser manuais, ou seja, quando a leitura é feita por um operador em cada um dos sensores. No caso de um sistema informatizado, o mesmo inclui um Dispositivo de Aquisição de Dados (DAQ), condicionadores de sinais para tratamento e filtragem, bem como conversores analógicos-digitais, para envio das informações a um computador [1].

Os sistemas DAQ também podem empregar wireless sensor network (WSN), atualmente utilizados no Monitoramento de Integridade Estrutural, inclusive para monitoramento de deformações, com o uso de strain gages [10], por meio de redes sem fio, o que pode oferecer inúmeras vantagens, tais como a redução de custos com a eliminação de fios e cabos, que no caso de monitoramento de grandes estruturas, representa um alto custo devido à grande quantidade de materiais e de mão-de-obra necessária à sua instalação. Além disso, a utilização de WSN proporciona maior flexibilidade, visto que a mesma pode ter sua configuração alterada com grande facilidade, ou seja, de acordo com a necessidade do projeto [12]. 
Contudo o uso de WSN apresenta algumas desvantagens se comparado a sistemas tradicionais, como por exemplo a necessidade de alimentação por meio de baterias, o que implica na necessidade de se utilizar sistemas capazes de otimizar o consumo de energia [12].

A escolha dos sensores está diretamente ligada à grandeza que se pretende monitorar, como por exemplo, a avaliação de patologias existentes ou do comportamento estrutural do elemento analisado [1]. No caso da avaliação das condições estruturais a medição de deformações pode fornecer diversas informações sobre as tensões sofridas pela estrutura em condições operacionais da mesma [13].

\subsection{Deformações e Deslocamentos}

Conhecer e analisar as tensões não é suficiente para o estudo da segurança em estruturas, sendo necessário também saber se as deformações ocorridas nos elementos estruturais não serão excessivas a ponto de prejudicar suas funcionalidades [14].

Quando uma estrutura é submetida a esforços externos, pequenas partículas que constituem a mesma deslocam-se até que ocorra o equilíbrio entre as forças internas e externas, fazendo com que ocorra deformação da estrutura até atingir este equilíbrio [15].

Frequentemente, em problemas de engenharia, a aplicação da Lei de Hooke [16] ocorre nas análises de estados de tensão, biaxiais e triaxiais [17], que em sua generalização, em um elemento tridimensional solicitado nas direções principais (Figura 1), possibilita a obtenção das deformações a partir da superposição dos

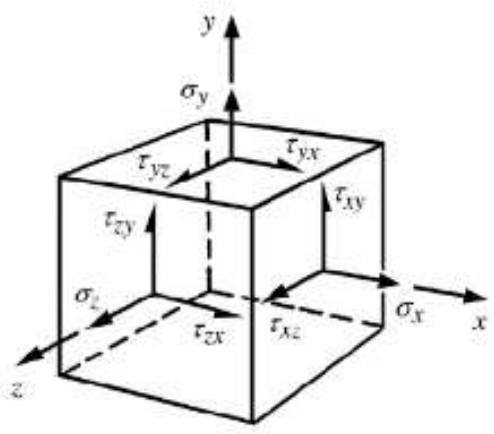

efeitos.

Figura 1: Elementos de tensão relativos aos eixos xyz [18]

Uma das formas de medição das deformações específicas é por meio de strain gages, que quando do tipo rosetas, ou seja, três strain gages num mesmo ponto, porém com direções distintas, onde os ângulos $\theta_{1}$, $\theta_{2}$ e $\theta_{3}$ (Figura2) são conhecidos, a determinação das deformações passa a ser conforme equações 1 a 3 [19].

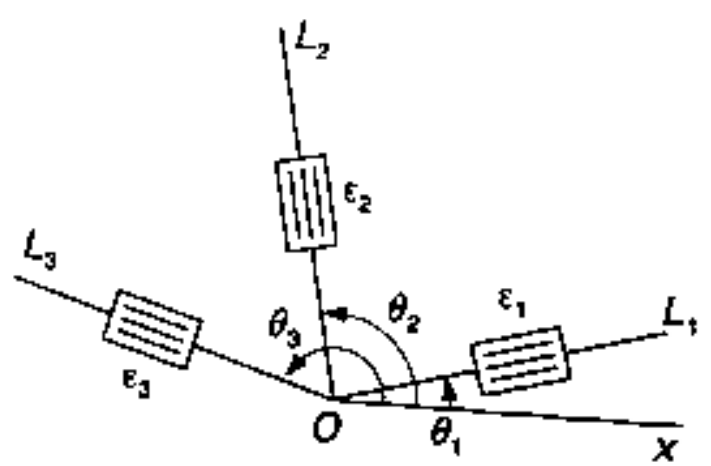

Figura 2: Roseta de Deformações com três strain gages [19]

$$
\begin{aligned}
& \varepsilon_{1}=\varepsilon_{x} \cos ^{2} \theta_{1}+\varepsilon_{y} \sin ^{2} \theta_{1}+\gamma_{y x} \sin \theta_{1} \cos \theta_{1} \\
& \varepsilon_{2}=\varepsilon_{x} \cos ^{2} \theta_{2}+\varepsilon_{y} \sin ^{2} \theta_{2}+\gamma_{y x} \sin \theta_{2} \cos \theta_{2} \\
& \varepsilon_{3}=\varepsilon_{x} \cos ^{2} \theta_{3}+\varepsilon_{y} \sin ^{2} \theta_{3}+\gamma_{y x} \sin \theta_{3} \cos \theta_{3}
\end{aligned}
$$


Por fim, a partir da mensuração das deformações $\varepsilon_{1}, \varepsilon_{2}$ e $\varepsilon_{3}$, é possível obter as deformações $\varepsilon_{x}$, $\varepsilon_{y} \mathrm{e}$ $\gamma_{y x}$, e consequentemente as tensões atuantes no ponto em análise.

O strain gage de resistência elétrica (Figura 3), é um dos sensores para medição de deformações mais utilizados e com um grande campo de aplicação. O princípio de seu funcionamento está baseado na alteração da resistência elétrica de seu condutor, uma vez que este encontra-se fixado em um elemento estrutural, e que à medida que este deforma-se o sensor sofre a mesma deformação e consequentemente altera a resistência elétrica, de forma proporcional à deformação específica [1].

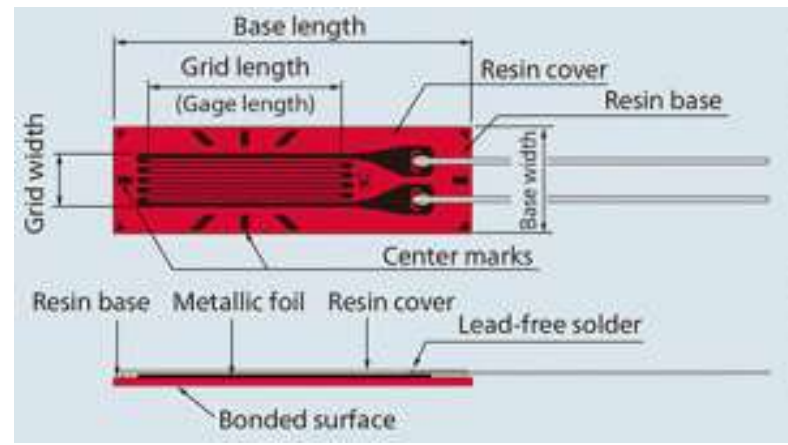

Figura 3: Strain gage uniaxial de resistência elétrica adaptado de [20]

Quanto aos deslocamentos em estruturas, ou ainda, deflexões em eixos retos, podem ser definidos como sendo a mudança de posição dos eixos dos baricentros das barras, nas direções $x, y$, e $z$, como no caso da Figura 4, onde a o eixo reto da viga ganha novo formato após a aplicação de uma carga. Sendo que sua verificação constitui importante elemento das etapas de análise e de projeto de uma estrutura, visto que se os deslocamentos ultrapassarem os limites desejáveis, pode-se implicar em situação desagradável e que comprometam alguma funcionalidade da estrutura $[14,16]$.

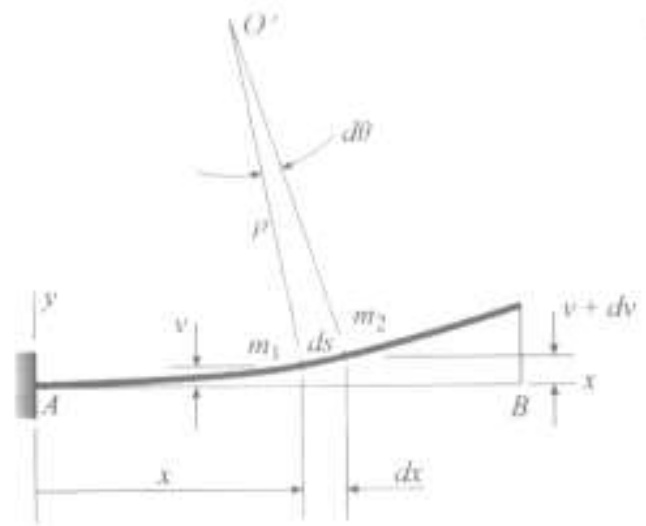

(a)

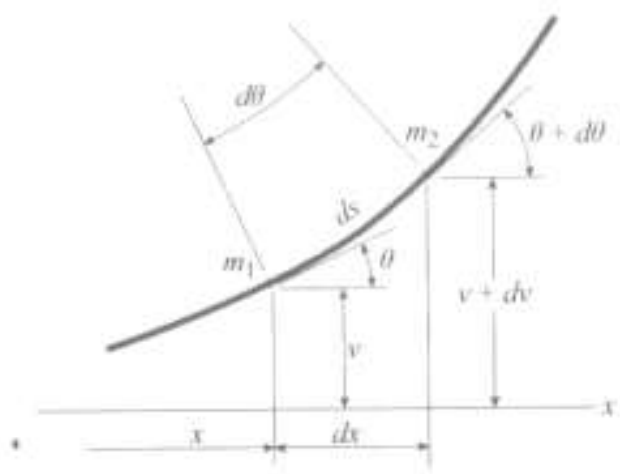

(b)

Figura 4: Curva de deslocamento de uma viga engastada (a), com ampliação (b) [21]

Para medição de deslocamentos podem ser utilizados sensores baseados nos mais diversos princípios, como mecânicos, ópticos e elétricos, a exemplo do transdutor potenciométrico linear, que relaciona a resistência e o comprimento de seu condutor. Ou seja, à medida que o cursor do potenciômetro é movimentado, devido ao deslocamento da estrutura, o valor da resistência também é alterado, podendo assim ser convertida a variação de resistência em variação de comprimento a partir de uma calibração inicial do equipamento [1]. 


\section{MATERIAIS E MÉTODOS}

\subsection{Desenvolvimento do Sistema}

Foi desenvolvido um sistema de aquisição de dados, que foi denominado e-structure, sendo composto por hardware (Figura 5) e software, para aquisição e processamento de dados relativos a sensores de deformação (strain gages), de deslocamento e força (células de carga). Foram criados sete canais, sendo quatro com $1 / 4$ de Ponte de Wheatstone (PW), um canal com $1 / 2 \mathrm{PW}$, um canal para PW completa e um canal para transdutor potenciométrico de deslocamento. A maior quantidade de canais para ligações de $1 / 4 \mathrm{de} \mathrm{PW}$, foi feita para que fosse possível a ligação de strain gages tipo rosetas, os quais necessitam de três canais.

O sistema foi desenvolvido a partir da utilização da plataforma Arduino, mais especificamente por meio da placa modelo $M E G A$, uma vez que esta possui quantidade suficiente de portas de saídas e entradas analógicas e digitais, compatíveis com a quantidade de canais empregadas no sistema em questão.

No caso da aquisição de dados referentes a deformação, foi necessário empregar junto ao Arduino, amplificadores de sinais e circuitos elétricos tipo Ponte de Wheatstone, com resistores shunt, para calibração pelo método indireto. O amplificador utilizado, foi o módulo HX711, o qual além de amplificar os sinais em até 128 vezes, efetua a conversão analógica-digital (AD) numa taxa de 24 bits, ou seja, superior aos 10 bits do Arduino MEGA.

Junto ao Arduino MEGA, foi instalado um módulo HC-05 de comunicação Bluetooth, para envio e recepção de transmissões, pelas portas $R X$ e $T X$, via comunicação serial, com um smartphone . O módulo HC05 utiliza Bluetooth V2.0, com um Enhanced Data Rate de 3 Mbps e um Transceptor de rádio de 2.4 GHz.

O custo com todos os materiais empregados na construção do hardware ficou em torno de US\$ 89,00, conforme descrição resumida constante da Tabela 1. Enquanto que o equipamento comercial de referência, utilizado na pesquisa foi um aquisitor modelo QuantumX-MX840A do fabricante HBM ${ }$, que foi adquirido em setembro de 2011 pelo valor de $\mathrm{R} \$ 14.571,43$.

Tabela 1: Custos estimados para construção do hardware do $D A Q$

\begin{tabular}{|c|c|c|c|}
\hline DESCRIÇÃO DOS ITENS & US\$ UNIT & QUANT. & US\$ TOTAL \\
\hline Arduino Mega 2560 - R3 ${ }^{12}$ & 35,0 & 1 & 35 \\
\hline Protoshield para Arduino Mega ${ }^{1}$ & 5,0 & 1 & 5 \\
\hline Módulo Bluetooth $\mathrm{HC}-05^{1}$ & 8,0 & 1 & 8 \\
\hline Módulo Amplificador HX711 1 & 3,5 & 6 & 21 \\
\hline $\begin{array}{l}\text { Outros componentes eletrônicos (resistor, terminal, } \\
\text { fios, soldas, conector, placa de fenolite, interrupto- } \\
\text { res, potenciômetros e fotoacoplador) }\end{array}$ & & & 20,0 \\
\hline \multicolumn{3}{|l|}{ Total } & 89,0 \\
\hline
\end{tabular}

${ }^{1}$ Custos praticados nos valores baseados no site Amazon.com em julho/2018 (taxas e fretes não inclusos); ${ }^{2}$ Foi considerada uma placa Arduino original, porém com a placa clone o custo da mesma seria de aproximadamente US\$ 10,0; ${ }^{3}$ Custo Estimado; Mão-de-obra não inclusa. 


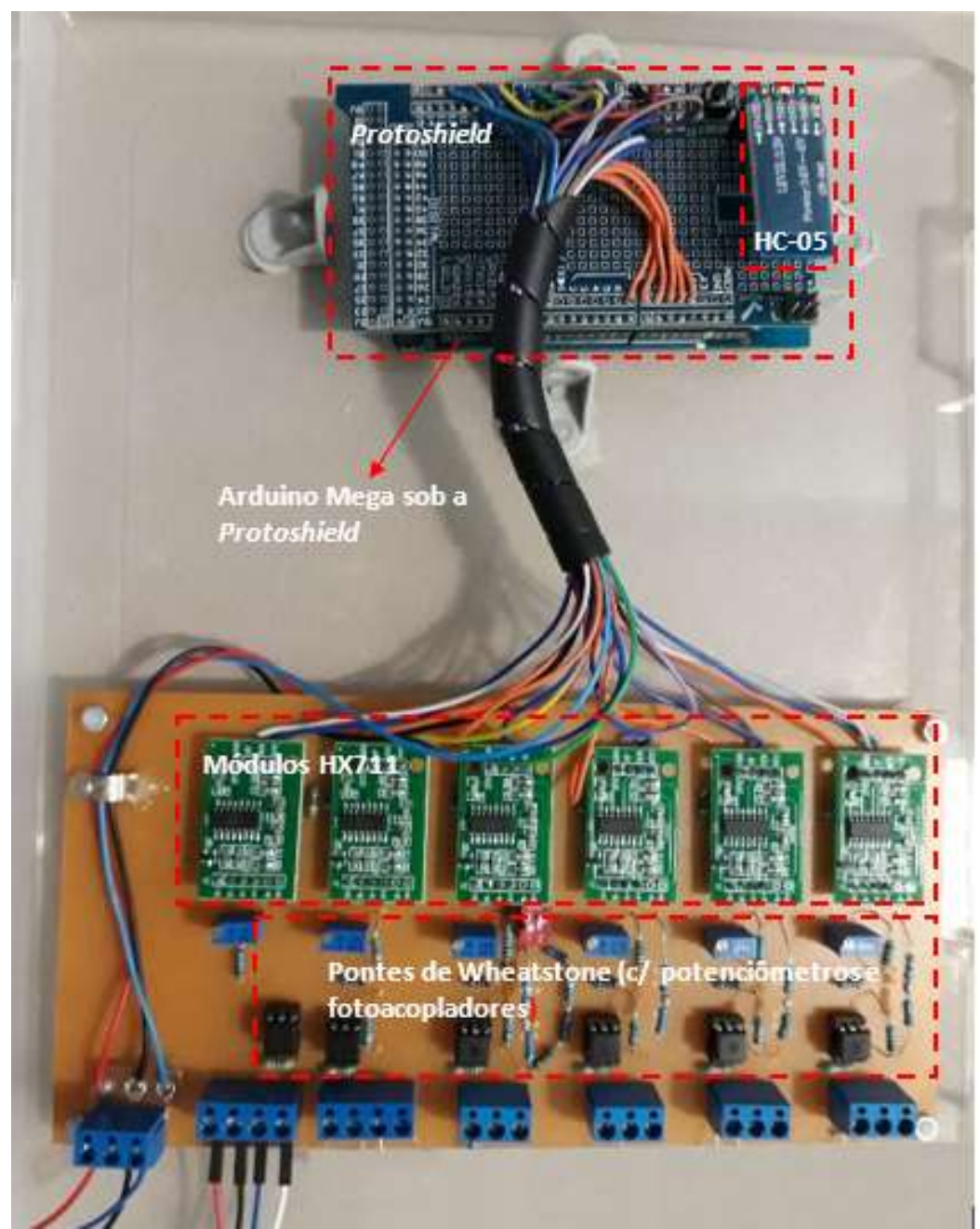

Figura 5: Hardware do sistema e-structure.

O Arduino foi programado com o firmware, por meio do Arduino Integrated Development Environment (IDE) ou Arduino Software, onde foi preparada a aquisição de dados de cada um dos canais, bem como o envio das leituras pela porta serial1, responsável pela comunicação Bluetooth. Além disto, também foi programado o controle dos fotoacopladores para acionamento dos resistores shunt, responsáveis pela calibração de parte do sistema.

Tanto o controle do hardware quanto o processamento dos dados são realizados por um aplicativo mobile (software) desenvolvido especificamente para este sistema de aquisição de dados, para utilização em dispositivos móveis como smartphones e tablets, que disponham de sistema operacional (OS) Android. Este aplicativo foi desenvolvido por meio da plataforma web MIT App Inventor [22], open source, desenvolvida pela Google ${ }^{\circledR}$ e atualmente mantida pelo Massachusetts Institute of Technology (MIT).

As duas principais telas do aplicativo são as de Aquisição de Dados (Figura 6a) e de Análise de Deformações em Rosetas (Figura 6b), sendo que a tela de Aquisição possui a conexão Bluetooth, bem como a leitura dos 7 canais, com a entrada de dados para calibração de cada um dos canais, os quais estão associados aos botões de calibração. Também é possível escolher quais canais serão habilitados. $\mathrm{O}$ aplicativo também conta com o recurso de média móvel que pode ser habilitado a critério do usuário do sistema. 

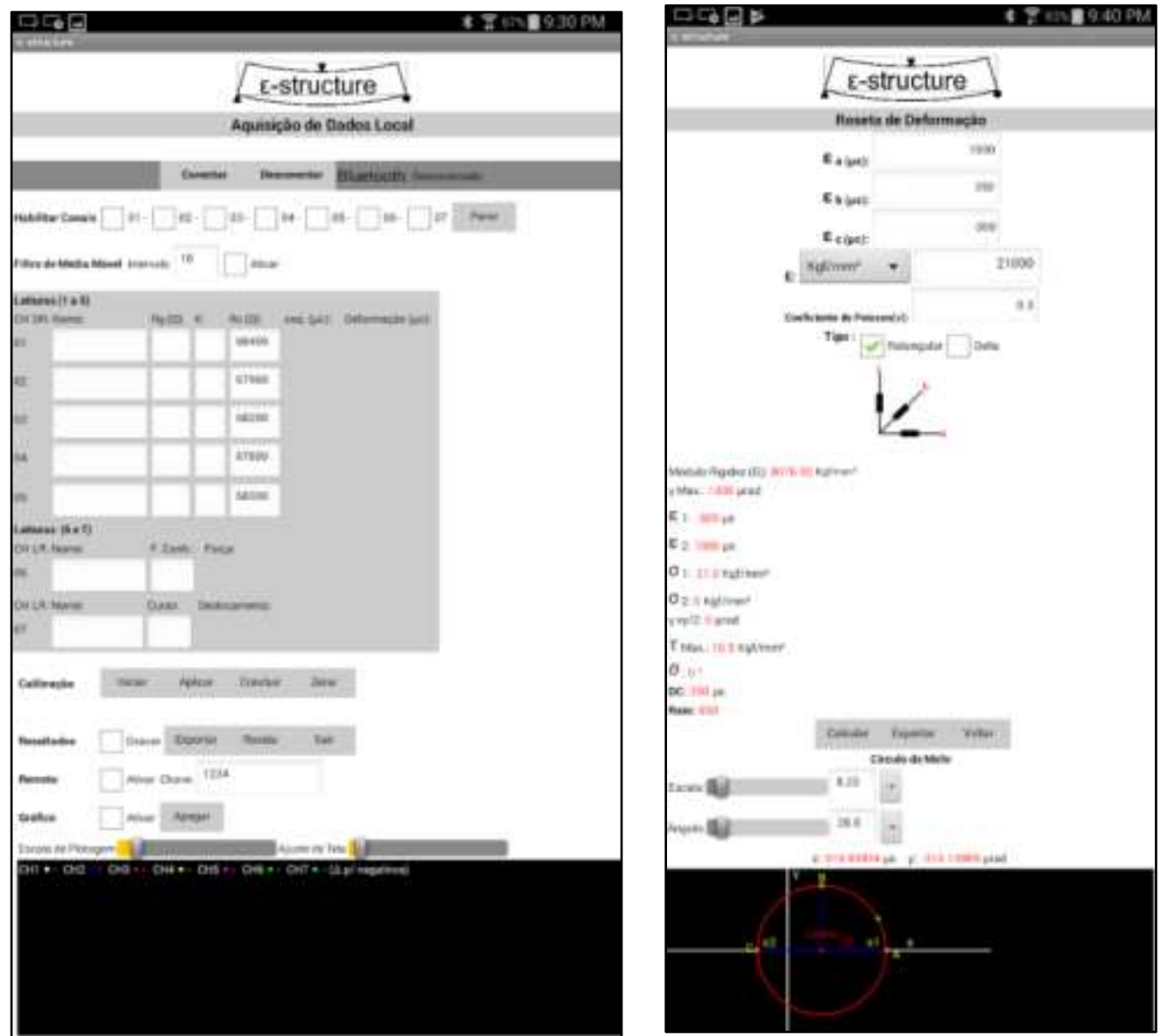

Figura 6: Tela de Aquisição de Dados (a) e Análise de Deformações e Círculo de Mohr (b).

Os dados coletados são exibidos em cada um dos canais e podem ser gravados e exportados como arquivos "csv" (comma separated values), para utilização em softwares de planilhas eletrônicas como, por exemplo, MS Excelß. Ainda na tela de aquisição, os dados aquisitados podem ser exibidos num chart com fundo preto em forma de gráfico de dispersão e compartilhados remotamente via internet.

Na tela Análise de Deformações são recebidos os dados de leituras dos canais 1, 2 e 3, que correspondem a um strain gage tipo roseta. Nesta tela são inseridas informações complementares como Módulo de Elasticidade e Coeficiente de Poisson, onde são determinados os valores de deformações e tensões principais. A partir dos valores calculados pelo aplicativo, é desenhado o Círculo de Mohr de Deformações, onde é possível visualizar a deformação em qualquer uma das direções com o ajuste do cursor em $360^{\circ}$. Os resultados da análise de deformações e tensões, podem ser compartilhados na forma de texto mediante extensão ".txt" referente aos cálculos e desenho do Círculo de Mohr de Deformações através de imagem no formato ".png" (Portable Network Graphics).

Os dados aquisitados pelos 7 canais (Figura 7) podem ser transmitidos em tempo real via internet, através do servidor Firebase ${ }^{\circledR}$ para o mesmo aplicativo instalado em outros dispositivos móveis com conexão à internet, ou ainda para o browser de qualquer navegador. 


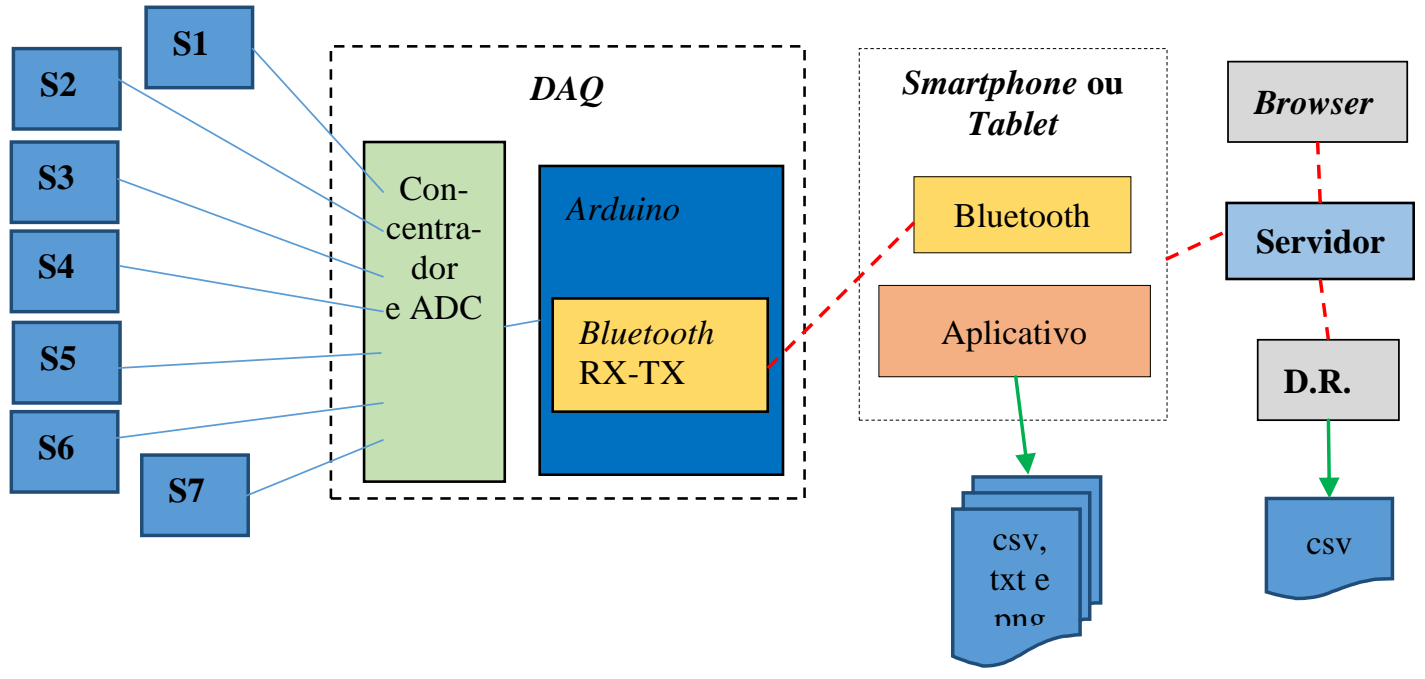

Figura 7: Estrutura de funcionamento do sistema $e$-structure.

\subsection{Ensaio de Deformação, Deslocamento e Força em Lâmina Metálica}

Inicialmente o sistema $e$-structure foi testado no monitoramento de deformações de uma lâmina de aço com medidas de 50,7 mm x 4,78 $\mathrm{mm}$ x 400,0 $\mathrm{mm}$ (largura $\mathrm{x}$ altura x comprimento), na condição de viga isostática (engastada em uma extremidade e livre na outra) sob flexão simples, mediante aplicação de uma força transversal, com um strain gage tipo roseta retangular (modelo KFG-5-120-D17-11), distanciado a 290,0 mm do ponto de aplicação da força (Figura 8). Foi realizada a aplicação de forças (F), nos valores de 26,95 N, 40,67 $\mathrm{N}$ e 101,43 $\mathrm{N}$ valores estes das anilhas disponíveis para o experimento, que não causariam deformações excessivas na lâmina.

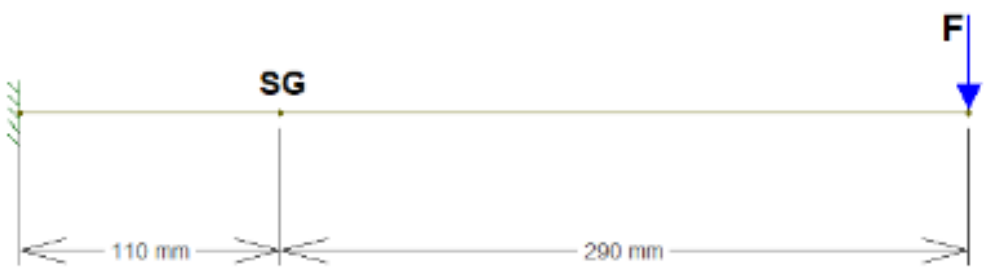

Figura 8: Disposição esquemática da lâmina metálica com strain gage (SG) tipo roseta.

Para os testes dos canais de leituras de deslocamento e força, outra lâmina de aço, com as medidas de 22,22 mm x 4,76 mm x 432,0 mm (largura x altura x comprimento), foi ensaiada sob flexão simples, tal como a lâmina anterior, sendo que o ponto de medição de deslocamento foi a 87,00 $\mathrm{mm}$ do ponto de aplicação de força $(\mathrm{F})$, conforme Figura 9. Foi utilizado um transdutor da marca Gefran ${ }^{\circledR}$, modelo PY-3-F-025-S01M para medição de deslocamentos e uma célula de carga da marca Guang-CE®, modelo YZC-516C/1kN para medição de força. Inicialmente foram utilizados 3 valores de forças para carregamentos da lâmina. Entretanto, como os resultados não foram satisfatórios para o pesquisador, o ensaio foi realizado com 6 valores de forças (F), ou seja, de 6,28 N, 11,38 N, 16,68 N, 21,78 N, 27,08 N e 32,96 N.

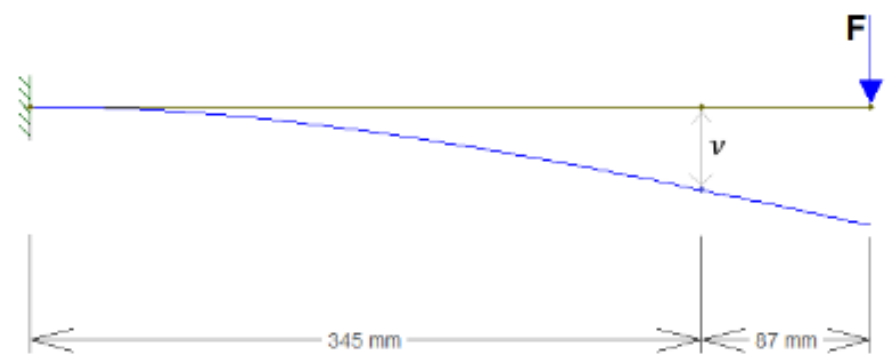

Figura 9: Disposição esquemática da lâmina metálica com ponto de medição do deslocamento $(v)$ 
Os ensaios de ambas as lâminas, ou seja, de deformação, deslocamento $(v)$ e força $(F)$, também foram repetidos com a aquisição de dados com um equipamento comercial de referência, um aquisitor QuantumXMX840A do fabricante HBM®, para comparação dos resultados entre o mesmo e o e-structure. Tais resultados também foram comparados aos valores de deformação específica $(\varepsilon)$ e deslocamento $(v)$, determinados analiticamente pelas equações 4 e 5 .

$$
\begin{aligned}
& v=\frac{F x^{2}}{6 E I}(3 L-x) \\
& \varepsilon=\frac{F x y}{E I}
\end{aligned}
$$

A análise comparativa entre os resultados experimentais $\left(\hat{x}_{i}\right)$ e analíticos $\left(x_{i}\right)$, foi feita por meio da determinação do erro relativo percentual (ER\%), conforme equação 6.

$$
E R \%=\left(\frac{x_{i}-\hat{x}_{i}}{x_{i}}\right) 100
$$

\subsection{Ensaio de Deformação em Viga de Concreto Armado}

O sistema $e$-structure também foi testado em ensaios de deformação com carregamento dinâmico (incremento continuo de força), no ensaio de vigas de concreto armado sob flexão. Tais vigas foram feitas nas dimensões de $12,5 \mathrm{~cm}$ de largura, $23,5 \mathrm{~cm}$ de altura e $132 \mathrm{~cm}$ de comprimento, dimensões estas e armadura proposta por [23], uma vez que tal viga foi utilizada em outros projetos de pesquisa junto ao Laboratório da Instituição em que se realizou esta pesquisa.

As vigas tiveram sua armadura longitudinal instrumentada com dois strain gages tipo BX120-3AA e

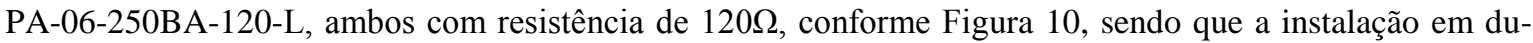
plicidade de ambos sensores (E1 e E2), se deu pelo fato de que as leituras dos mesmos ocorreram simultaneamente tanto pelo sistema proposto nesta pesquisa (e-structure), quanto pelo aquisitor de dados comercial de referência (QuantumX-MX840A).
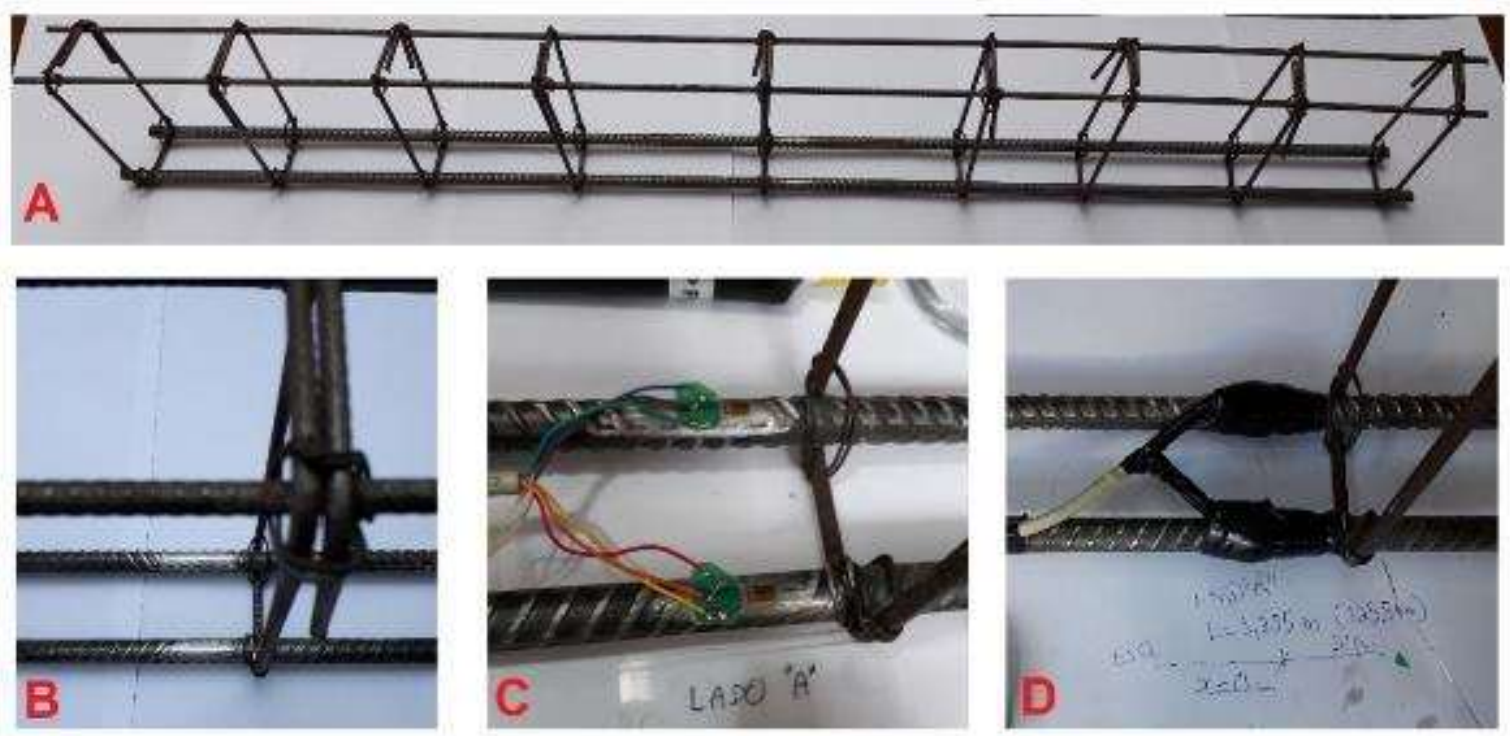

Figura 10: A) Armadura da viga; B) Preparo da superfície; C) Instalação dos strain gages; D) Proteção dos strain gages.

O ensaio realizado foi do tipo flexão a 4 pontos, com aplicação de forças até a fissuração e/ou ruptura da viga, conforme esquema da Figura 11. 


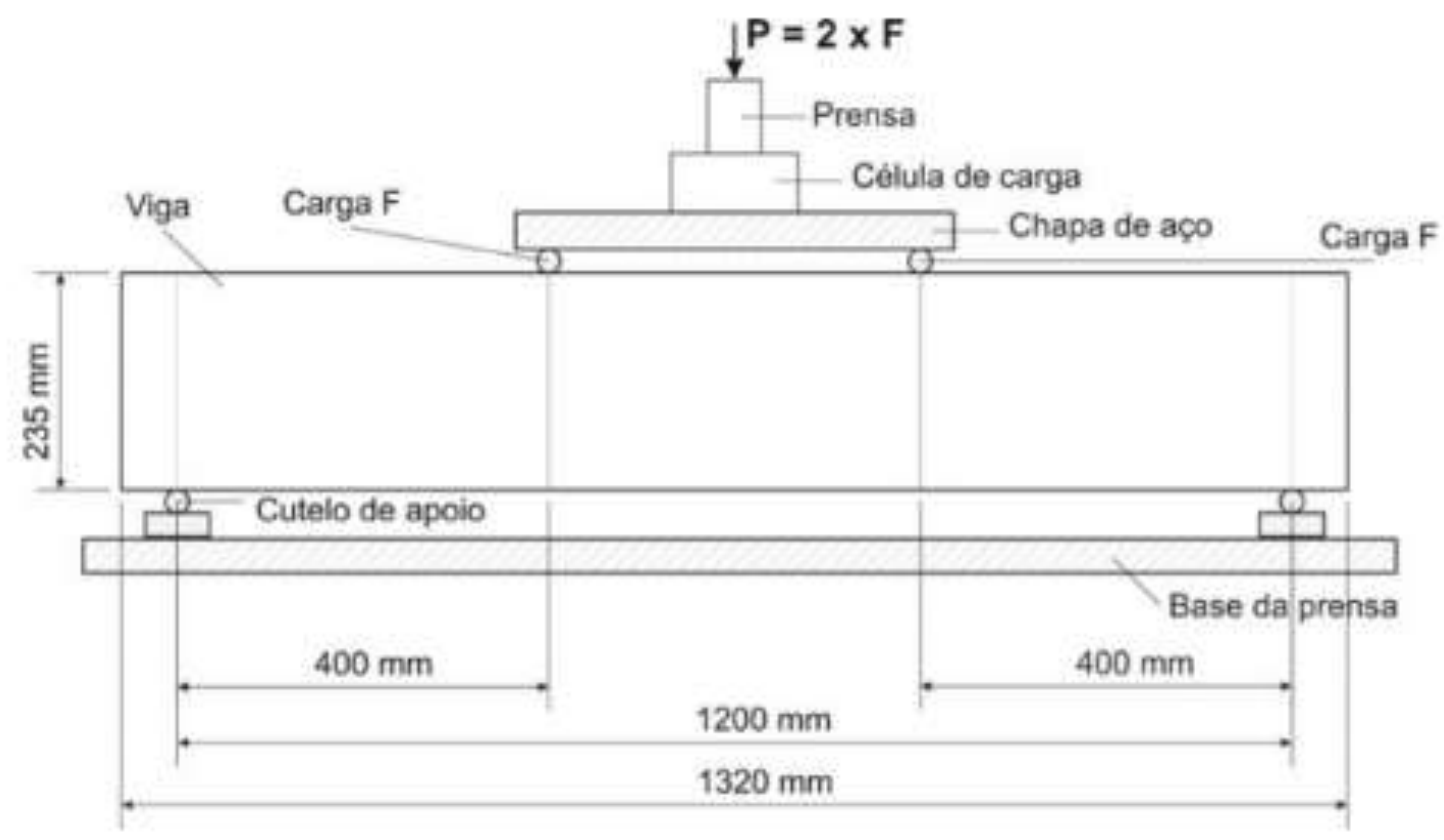

Figura 11: Esquema do ensaio de flexão à 4 pontos (Fonte: adaptado de [23])

A análise dos dados se deu por comparação gráfica, na forma de sobreposição das leituras de ambos equipamentos, bem como por meio da determinação da média dos erros relativos (MER), conforme equação 7, nos trechos de aplicação de força e determinação do Coeficiente de correlação de Pearson ( $r$ ), por meio do MS Excel®.

$M E R=\frac{1}{N} \sum_{i=1}^{N} \sqrt{\left(\frac{x_{i}-\hat{x}_{i}}{x_{i}}\right)^{2}}$

\section{RESULTADOS}

\subsection{Lâmina Metálica - Deformação, Deslocamento e Força}

O ensaio de deformação (Figura 12) resultou em pequenas diferenças entre as leituras experimentais, bem como em relação aos valores analíticos, conforme comparação gráfica (Figura 13) e erros relativos apresentados na Tabela 2, os quais não chegaram a atingir 5\% em relação ao valor analítico, sendo que os percentuais negativos representam valores experimentais menores que os de referência.
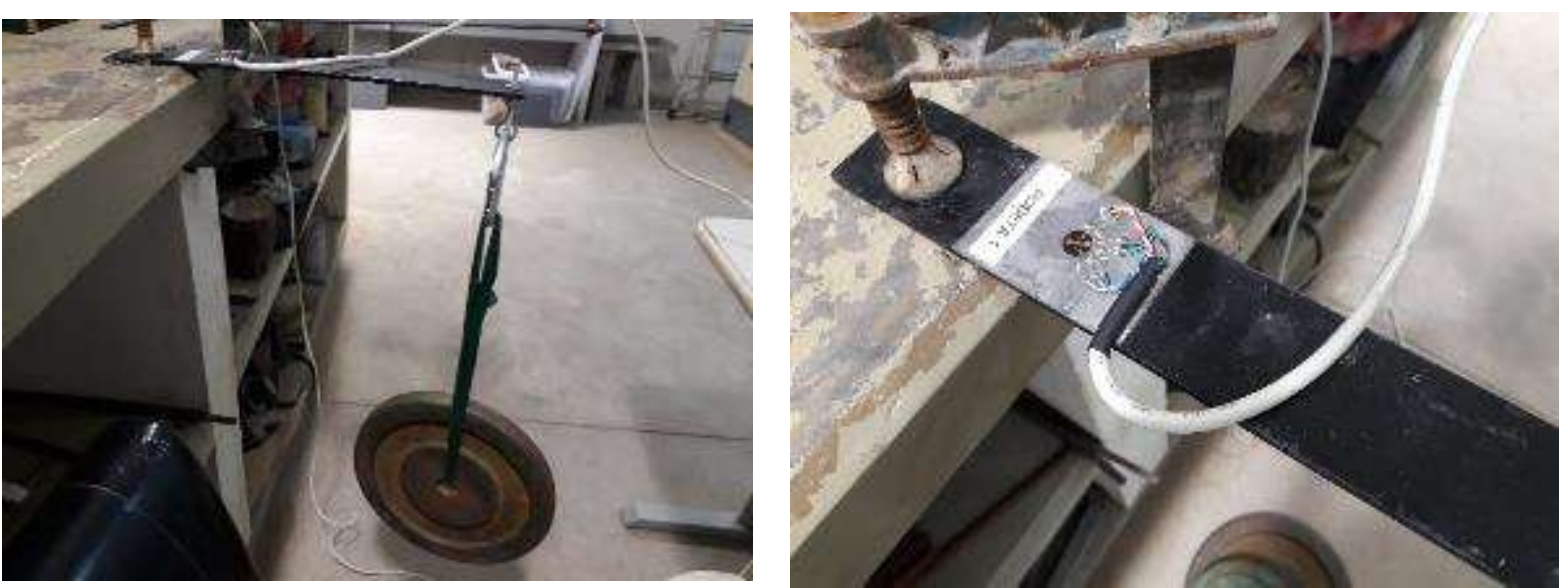

Figura 12: Lâmina metálica com strain gage tipo roseta, durante ensaio de deformação. 
Tabela 2: Valores de Deformações Específicas e de Erros Relativos.

\begin{tabular}{|c|c|c|c|c|c|c|c|}
\hline \multirow{4}{*}{$\begin{array}{l}\text { EN- } \\
\text { SAIO }\end{array}$} & \multirow[t]{4}{*}{ FORÇA (N) } & \multicolumn{5}{|c|}{ Deformação } & \multirow{4}{*}{$\begin{array}{c}\text { ERRO RELATI- } \\
\text { VO ENTRE } \\
\text { EQUIPAMEN- } \\
\text { TOS (\%) }\end{array}$} \\
\hline & & \multirow{3}{*}{$\begin{array}{c}\text { ANALÍTICA } \\
(\mu \mathrm{m} / \mathrm{m})\end{array}$} & \multicolumn{4}{|c|}{ Experimental $^{1}$} & \\
\hline & & & \multicolumn{2}{|c|}{ QUANTUM X } & \multicolumn{2}{|c|}{ E-STRUCTURE } & \\
\hline & & & $(\mu \mathrm{m} / \mathrm{m})$ & Erro (\%) & $(\mu \mathrm{m} / \mathrm{m})$ & Erro (\%) & \\
\hline 1 & 26,95 & 196,70 & 205,12 & 4,28 & 187,20 & $-4,83$ & 8,74 \\
\hline 2 & 40,67 & 296,83 & 302,26 & 1,83 & 298,99 & 0,73 & 1,08 \\
\hline 3 & 101,43 & 740,30 & 765,36 & 3,39 & 764,87 & 3,32 & 0,06 \\
\hline
\end{tabular}

1Valores médios de 3 medições

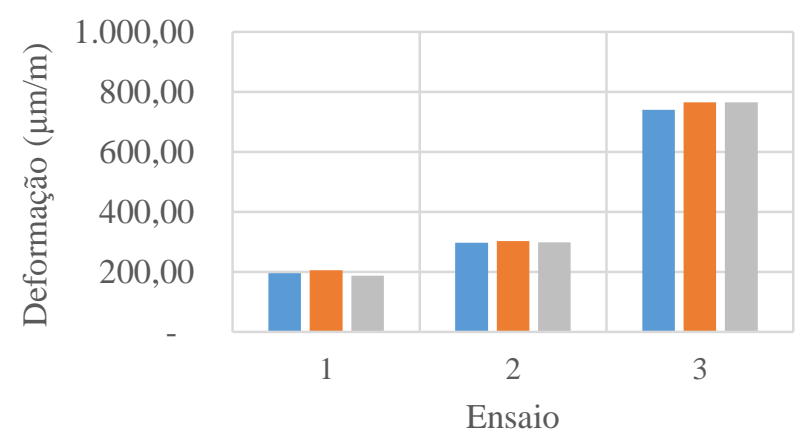

- Analytical $\quad$ QuantumX $\quad$ e-structure

Figura 13: Comparação gráfica dos valores de deformação para cada aplicação de força.

Quanto ao ensaio de deslocamento (Figura 14), o e-structure apresentou um erro relativo médio de $28,96 \%$, com um desvio padrão do erro médio de $1,5 \%$ em relação aos valores analíticos. Quanto ao aquisitor de referência, o mesmo apresentou um erro relativo médio de $19,14 \%$, ou seja, menor que do sistema desta pesquisa, entretanto o desvio padrão do erro médio foi de $+/-16,03 \%$.

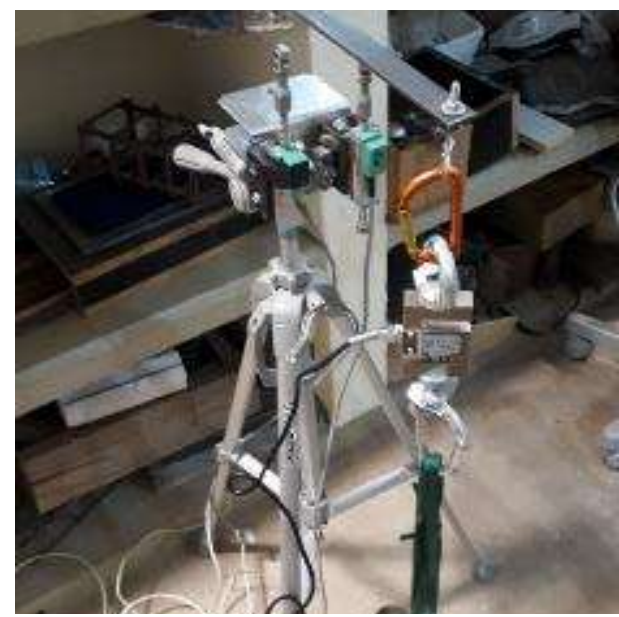

Figura 14: Lâmina metálica durante ensaio de deslocamento e medição de força.

Também foi constatado que à medida que os deslocamentos aumentavam, o erro relativo entre ambos equipamentos diminuía (Tabela 3 ), bem como os valores de deslocamento lidos pelo $e$-structure, sempre ficaram maiores que os valores analíticos, enquanto que no caso do aquisitor de referência, isto somente aconteceu a partir da terceira aplicação de força (Figura 15). 
Tabela 3: Valores de Deslocamento e Erros Relativos.

\begin{tabular}{|c|c|c|c|c|c|c|c|c|c|}
\hline \multirow{4}{*}{ ENSAIO } & \multirow{4}{*}{\begin{tabular}{|c|}
$\begin{array}{c}\text { FORÇA } \\
\text { (N) }\end{array}$ \\
\end{tabular}} & \multicolumn{7}{|c|}{ DESLOCAMENTOS } & \multirow{4}{*}{$\begin{array}{c}\text { ERRO RELATI- } \\
\text { VO ENTRE } \\
\text { EQUIPAMENTOS } \\
(\%)\end{array}$} \\
\hline & & \multirow[b]{3}{*}{$\begin{array}{c}\text { ANALÍTICO } \\
(\mathrm{mm})\end{array}$} & \multicolumn{6}{|c|}{ EXPERIMENTAL' ${ }^{1}$} & \\
\hline & & & \multicolumn{3}{|c|}{ QUANTUM X } & \multicolumn{3}{|c|}{ E-STRUCTURE } & \\
\hline & & & $(\mathrm{mm})$ & \begin{tabular}{l|} 
Desvio \\
Padrão \\
\end{tabular} & Erro (\%) & $(\mathrm{mm})$ & $\begin{array}{l}\text { Desvio } \\
\text { Padrão } \\
\end{array}$ & Erro (\%) & \\
\hline 1 & 6,28 & 3,02 & 1,53 & 0,70 & $-49,34$ & 3,96 & 0,01 & 31,13 & 158,82 \\
\hline 2 & 11,38 & 5,48 & 4,88 & 0,79 & $-10,95$ & 6,95 & 0,19 & 26,82 & 42,42 \\
\hline 3 & 16,68 & 8,03 & 8,23 & 0,52 & 2,49 & 10,31 & 0,21 & 28,39 & 25,27 \\
\hline 4 & 21,78 & 10,49 & 11,99 & 0,62 & 14,3 & 13,6 & 0,19 & 29,65 & 13,43 \\
\hline 5 & 27,08 & 13,04 & 15,31 & 0,70 & 17,41 & 16,71 & 0,21 & 28,14 & 9,14 \\
\hline 6 & 32,96 & 15,87 & 19,1 & 0,98 & 20,35 & 20,57 & 0,09 & 29,62 & 7,7 \\
\hline
\end{tabular}

1Valores médios de 3 medições

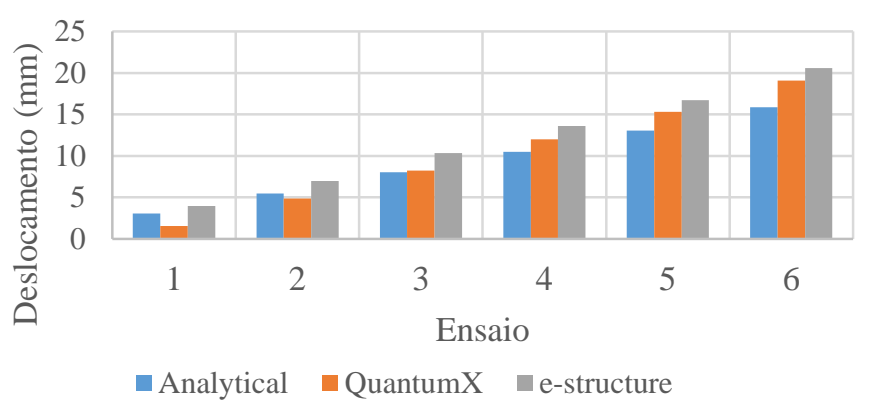

Figura 15: Comparação gráfica dos valores de deslocamento para cada aplicação de força.

Em relação a medição de forças, as variações resultaram em pequenas diferenças entre as leituras experimentais, bem como em relação aos valores de referência, conforme comparação gráfica (Figura 16) e erros relativos apresentados na Tabela 4 , os quais não chegaram a atingir $5 \%$ no $e$-structure e $2 \%$ no aquisitor de referência, em relação aos valores analíticos. Bem como, apresentaram baixo desvio padrão em ambos os equipamentos.

Tabela 4: Valores de Forças e Erros Relativos.

\begin{tabular}{|c|c|c|c|c|c|c|c|c|}
\hline \multirow[t]{3}{*}{ ENSAIO } & \multirow{3}{*}{$\begin{array}{c}\text { FORÇA } \\
\text { CONHECIDA } \\
\text { (N) }\end{array}$} & \multicolumn{6}{|c|}{ FORÇA EXPERIMENTAL ${ }^{1}$} & \multirow{3}{*}{$\begin{array}{c}\text { ERRO RELATI- } \\
\text { VO ENTRE } \\
\text { EQUIPAMENTOS } \\
(\%)\end{array}$} \\
\hline & & \multicolumn{3}{|c|}{ QUANTUM X } & \multicolumn{3}{|c|}{ E-STRUCTURE } & \\
\hline & & (N) & $\begin{array}{l}\text { Erro } \\
(\%)\end{array}$ & $\begin{array}{l}\text { Desvio } \\
\text { Padrão } \\
\end{array}$ & $(\mathrm{N})$ & \begin{tabular}{l|}
$\begin{array}{l}\text { Erro } \\
(\%)\end{array}$ \\
\end{tabular} & $\begin{array}{l}\text { Desvio } \\
\text { Padrão } \\
\end{array}$ & \\
\hline 1 & 6,28 & 6,18 & $-1,59$ & 0,00 & 5,98 & $-4,78$ & 0,01 & $-3,24$ \\
\hline 2 & 11,38 & 11,28 & $-0,88$ & 0,01 & 11,09 & $-2,55$ & 0,00 & $-1,68$ \\
\hline 3 & 16,68 & 16,48 & $-1,2$ & 0,01 & 16,28 & $-2,4$ & 0,01 & $-1,21$ \\
\hline 4 & 21,78 & 21,68 & $-0,46$ & 0,00 & 21,39 & $-1,79$ & 0,01 & $-1,34$ \\
\hline 5 & 27,08 & 26,88 & $-0,74$ & 0,00 & 26,49 & $-2,18$ & 0,02 & $-1,45$ \\
\hline 6 & 32,96 & 32,67 & $-0,88$ & 0,00 & 32,57 & $-1,18$ & 0,00 & $-0,31$ \\
\hline
\end{tabular}

1Valores médios de 3 medições 


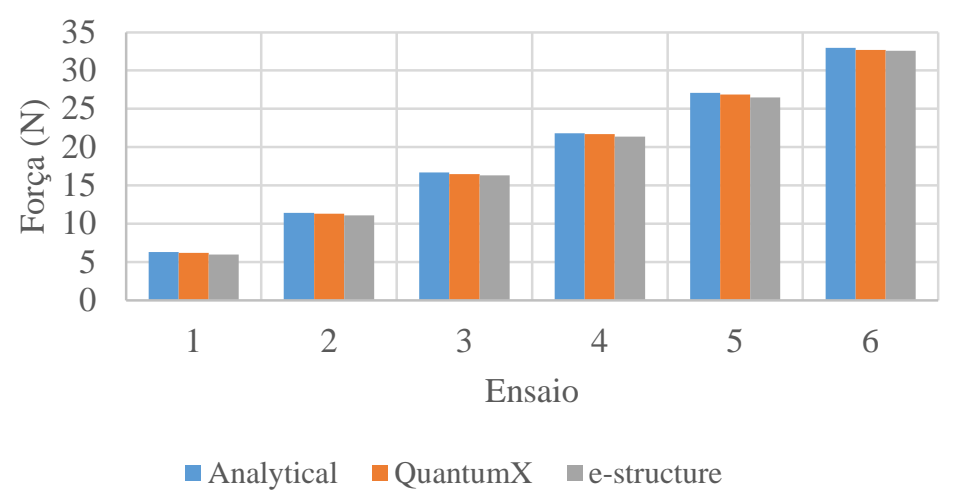

Figura 16: Comparação gráfica dos valores de forças para cada teste.

\subsection{Viga de Concreto Armado - Deformação Específica}

Os ensaios de flexão das vigas (Figura 17), tiveram a aquisição de dados simultânea dos dois strain gages (E1 e E2), sendo um pelo e-structure e o outro pelo aquisitor comercial de referência, numa frequência de $1,0 \mathrm{~Hz}$ [24]. Os resultados são apresentados nos gráficos da Figura 18, cujos valores do Coeficiente de correlação de Pearson (r) e média do erro relativo (MER) constam da Tabela 5.

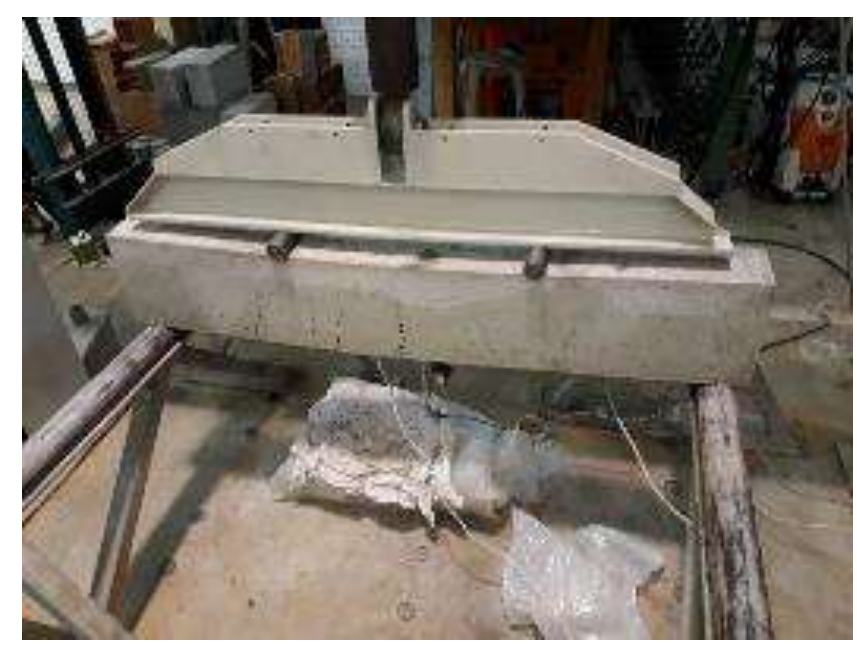

Figura 17: Viga n. ${ }^{\circ} 5$ em ensaio de flexão a quatro pontos.

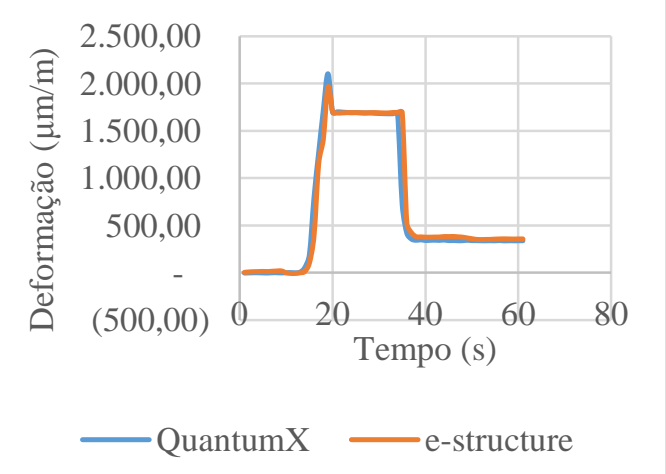

Figura 18a: Deformação da Viga . $^{\circ} 1$

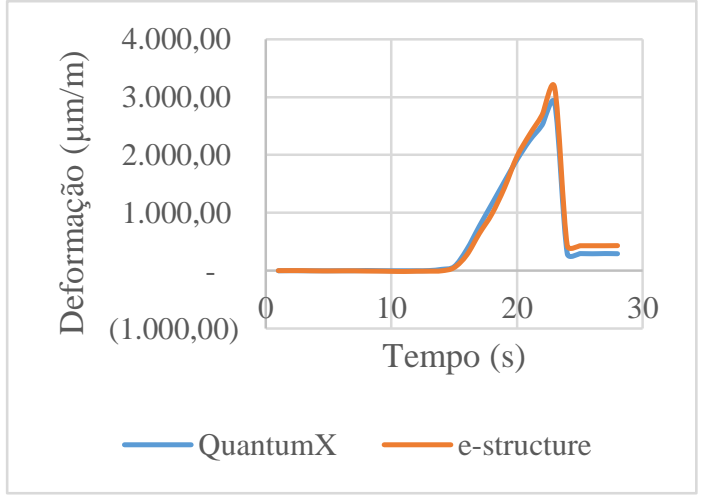

Figura 18b: Deformação da Viga n. ${ }^{\circ} 2$ 


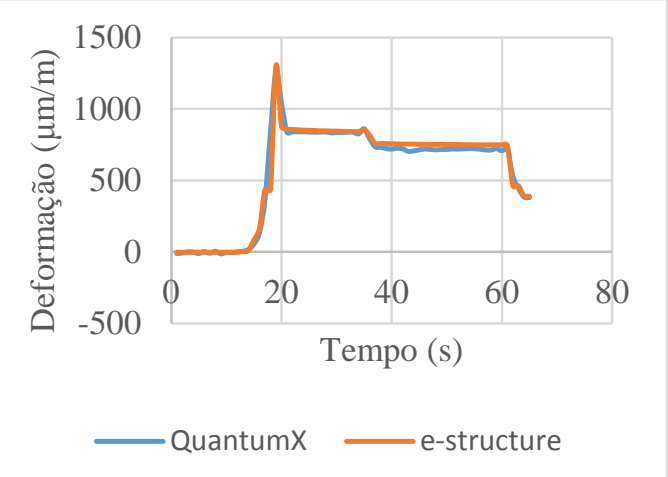

Figura 18c: Deformação da Viga n. ${ }^{\circ} 3$

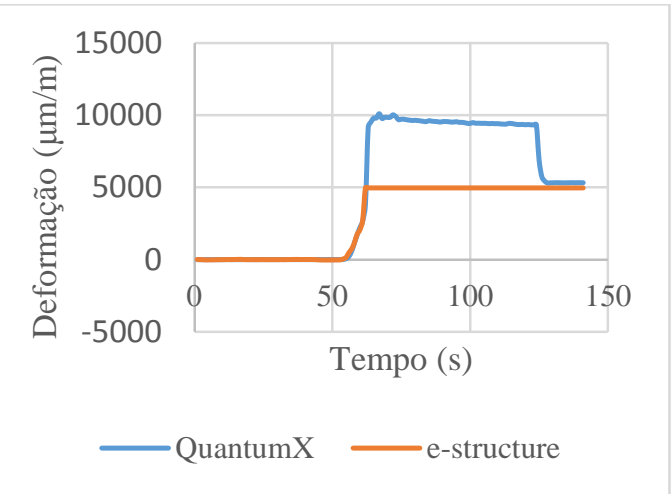

Figura 18e: Deformação da Viga n. ${ }^{\circ} 5$

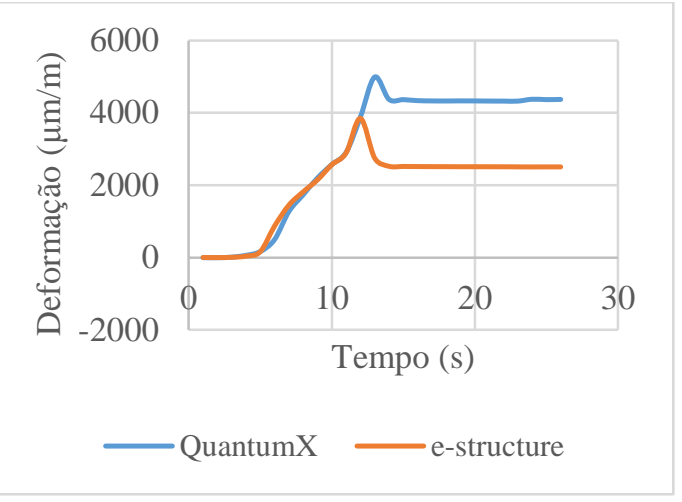

Figura 18d: Deformação da Viga n. ${ }^{\circ} 4$

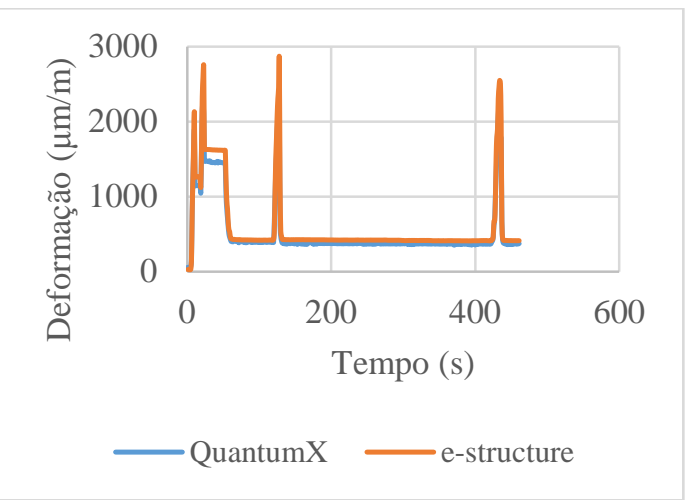

Figura 18f: Deformação da Viga n. ${ }^{\circ} 6$

No caso da viga n. ${ }^{\circ}$ 5, ocorreu um problema durante a execução do ensaio, ou seja, não foi realizado o ajuste inicial do fundo de escala de leituras do e-structure, o que limitou as leituras de deformação a aproximadamente $5.000 \mu \mathrm{m} / \mathrm{m}$, fazendo com que tal resultado não seja considerado. A viga n. $^{\circ} 4$, apresentou resultados notadamente insatisfatórios, visto que a média do erro padrão entre os equipamentos de aquisição foi de $31,79 \%$, ou seja, bem superior ao esperado.

Tabela 5: Coeficiente de Correlação de Pearson (r)

\begin{tabular}{c|c|c|c}
\hline VIGA & $\mathbf{r}$ & \multicolumn{2}{|c}{ MER } \\
\cline { 3 - 4 } & & $\%$ & INTERVALO (s) \\
\hline 1 & 0,977 & 15,39 & 14 a 41 \\
\hline 2 & 0,995 & 15,80 & 15 a 24 \\
\hline 3 & 0,985 & 6,94 & 14 a 65 \\
\hline 4 & 0,900 & 31,79 & 4 a 25 \\
\hline 5 & 0,951 & 45,26 & 55 a 128 \\
\hline 6 & 0,995 & 11,66 & 6 a 461 \\
\hline
\end{tabular}

Quanto as outras 4 vigas, ou seja, números 1, 2, 3 e 6, as mesmas apresentaram Coeficiente de correlação de Pearson de bons a ótimos, bem como média do erro padrão compatíveis com o esperado.

\section{CONCLUSÃO}

Para ensaios de curta duração, como os desta pesquisa, a utilização da plataforma Arduino, associada ao módulo amplificador HX711, mostraram-se compatível com a proposta de desenvolvimento de sistema para monitoramento de integridade estrutural de baixo custo, mediante aquisição, controle e transmissão de dados, especialmente aqueles relativos a deformações e forças, enquanto que os valores de deslocamento apresentaram resultados pouco satisfatórios para medidas menores que $10 \mathrm{~mm}$, o que pode ser explicado inclusive pela menor taxa de conversão AD do Arduino MEGA, que do módulo amplificador HX711, utilizado para leitura de deformações e forças. 
A utilização de um aplicativo mobile, desenvolvido especificamente para o sistema de monitoramento proposto, por meio da plataforma MIT App Inventor, permitiu a implementação de recursos personalizados à necessidade do sistema, como por exemplo, os procedimentos de calibração indireta, exibição gráfica de resultados e até mesmo a transmissão em tempo real via internet, sem que se fosse necessário lançar mão de recursos computacionais complexos e de difícil programação e utilização.

\section{BIBLIOGRAFIA}

[1] ANDRADE, R. G. M. DE., "Monitoramento de Curta Duração de uma Ponte Curva", Dissertação de M.Sc., USP, São Paulo, Brasil, 2012.

[2] SILVA, R. S. Y. R. C., "Monitoramento e Identificação Numérico e Experimental de Danos em Vigas e Pontes de Aço e Concreto Utilizando Transformadas de Wavelet", Tese de D.Sc., UNB, Brasília, DF, 2015. [3] SANTOS, L. O., "Monitoramento e ensaio de pontes", In: VII Congresso Brasileiro de Pontes e Estruturas, 110, Rio de Janeiro, RJ, Brasil, 21-23 Maio 2014.

[4] KLIKOWICZ, P., SALAMAK, M., POPRAWA, G., "Structural Health Monitoring of Urban Structures", Procedia Engineering, v. 161, pp. 958-962, 2016.

[5] BARONTINI, A., MASCIOTTA, M., RAMOS, L., et al., "An overview on nature-inspired optimization algorithms for Structural Health Monitoring of historical buildings", Procedia Engineering, v. 199, pp. 33203325, 2017.

[6] HAJDUKIEWICZ, M., BYRNE, D., KEANE, M., et al., "Real-time monitoring framework to investigate the environmental and structural performance of buildings", Building and Environment, v. 86, pp. 1-16, 2015.

[7] CHANDRASEKARAN, S., CHITHAMBARAM, T., KHADER, S. A., "Structural Health Monitoring of Offshore Structures Using Wireless Sensor Networking under Operational and Environmental Variability", International Journal of Environmental and Ecological Engineering, v. 10, n. 1, pp. 33-39, 2016.

[8] PINTO, C. S., DEGASPERI, F. T., "Desenvolvimento de uma interface para aquisição de dados experimentais utilizando o microcontrolador Arduino UNO", In: X Workshop de Pós-Graduação e Pesquisa do Centro Paula Souza. pp. 313-322, São Paulo, Out. 2015.

[9] ARDUINO, WHAT IS ARDUINO? https://www.arduino.cc/en/Guide/Introduction\#. Acessado em junho de 2018.

[10] LIANG, D., YUAN, S., "Structural health monitoring system based on multi-agent coordination and fusion for large structure", Advances in Engineering Software, v. 86, pp. 1-12, 2015.

[11] DEPARI, A., FERRARI, P., FLAMMINI, A., et al., "Development and evaluation of a WSN for realtime structural health monitoring and testing", Procedia Engineering, v. 87, pp. 680-683, 2014.

[12] FEDERICI, F., ALESIIA, R., COLARIETIA, A., et al., "Design of wireless sensor nodes for structural health monitoring applications", Procedia Engineering, v. 87, pp. 1298-1301, 2014.

[13] NI, Y., XIA, H., KO, J., et al., "Condition assessment of bridge deck truss using in-service monitoring", Bridge Maintenance, Safety, Management and Life-Cycle Optimization - Frangopol, Sause \& Kusko (eds)

Taylor \& Francis Group, pp. 185, 2010.

[14] ASSAN, A. E., Resistência dos Materiais, Editora da Unicamp, Campinas, 2010.

[15] TIMOSHENKO, S. P., Resistência dos Materiais, Traduzido da 3a ed. Livros Técnicos e Científicos, Rio de Janeiro, 1976.

[16] GERE, J. M., Mecânica dos Materiais, Pioneira Thomson Learning. São Paulo, 2003.

[17] RILEY, W. F., STURGES, L. D., MORRIS, D. H., Mecânica dos Materiais, Quinta ed., LTC, Rio de Janeiro, 2003.

[18] YOUNG, W. C., BUDYNAS, R. G., Roark's Formulas for Stress and Strain, Seventh ed. McGraw-Hill, New York, 2002.

[19] BEER, F. P., JOHNSTON, E. R., Resistência dos Materiais, 3a ed ed. McGraw-Hill, São PauloSP, 1995 . 
[20] KYOWA ELECTRONIC INSTRUMENTS CO., PRINCIPLES OF STRAIN GAGES,

http://www.kyowa-ei.com/eng/technical/strain_gages/principles.html. Acessado em julho de 2018.

[21] GERE, J. M., GOODNO, B. J., Mecânica dos Materiais, Sétima ed. Cengage Learning, São Paulo, 2015.

[22] MASSACHUSETTS INSTITUTE OF TECHNOLOGY, MIT APP IVENTOR 2,

http://appinventor.mit.edu/explore/. Acessado em março de 2017.

[23] BARROS, A. R. D. B., “Avaliação do Comportamento de Vigas de Concreto Auto-Adensável Reforçado Com Fibras de Aço”, Dissertação de M.Sc., UFAL, Mació, AL, 2009.

[24] SILVA, J . L. P. E, "Desenvolvimento de Sistema para Monitoramento de Estruturas com Utilização da Plataforma Arduino”, Dissertação de M.Sc., PUC-Campinas, Campinas, Brasil, 2018.

\section{ORCID}

João Batista Lamari Palma e Silve https://orcid.org/0000-0001-7115-6385

Ana Elisabete Paganelli Guimarães de Avila Jacintho https://orcid.org/0000-0001-5401-2160

Nadia Cazarim da Silva Forti https://orcid.org/0000-0001-9994-5546

Lia Lorena Pimentel https://orcid.org/0000-0001-5146-0451

Omar Carvalho Branquinho https://orcid.org/0000-0002-5193-8643 